\title{
CLINICOPATHOLOGIC FEATURES OF CERVICAL CANCER PATIENTS SEEN IN A COMPREHENSIVE CANCER CENTRE IN NORTH-WESTERN NIGERIA
}

\author{
${ }^{1}$ Usman M. A. \& ${ }^{* 2}$ Otene S. A. \\ ${ }^{I}$ Department of Radiotherapy and Oncology, Usman Danfodiyo University Teaching Hospital Sokoto, Sokoto State, Nigeria \\ ${ }^{* 2}$ Department of Oncology and Palliative Care, Federal Medical Centre, Makurdi, Benue State, Nigeria \\ *Corresponding Author E-mail: sammy4ng@yahoo.com, samuelotene@gmail.com Phone: +2348054456699
}

\begin{abstract}
The purpose of this study was to evaluate the socio-demographic and clinicopathological features of patients with cervical cancer seen in a comprehensive cancer center in North-western Nigeria. It was a six years retrospective study of patients with cervical cancer treated in the Department of Radiotherapy and Oncology, UDUTH, Sokoto. Data was obtained from the patients' case notes using a semi-structured data extraction form. A total of 220 cases were reviewed for patients whose mean age was 49.9 years ( $S D \pm 11.9$ ); with the age range of 24-87 years. Results show that squamous cell carcinoma was the most common histological type seen in 182(82.7\%) of the patients, followed by adenocarcinoma 22(10\%) and clear cell carcinoma 9(4.1\%). Vaginal bleeding 110(50\%), foul-smelling vaginal discharge103 (46.8\%), fatigue 67(30.5\%), lower abdominal pain 65(20.5\%) and weight loss 30(13.6\%) were the commonest clinical features. 176(80\%) patients presented late stages (IIB - IVB) of cervical cancer. Concluding, most of the women with cervical cancer presented with features of vaginal bleeding or foul-smelling vaginal discharge, weight loss, fatigue and lower abdominal pain, with commonest histological categorization being squamous cell carcinoma. Late presentation of the disease was obviously observed in most of the cases diagnosed. The clinical features of cervical cancer identified in the cases reviewed are indicators of advanced disease. Thus, it is imperative that advocacy for cervical cancer screening should be stepped up in order to ensure early detection and prevent the progression of the disease to advanced stages.
\end{abstract}

Keywords: Cervical Cancer, Chemotherapy, Clinicopathologic, Features, Patients.

LICENSE: This work by Open Journals Nigeria is licensed and published under the Creative Commons Attribution License 4.0 International License, which permits unrestricted use, distribution, and reproduction in any medium, provided this article is duly cited.

COPYRIGHT: The Author(s) completely retain the copyright of this published article.

OPEN ACCESS: The Author(s) approves that this article remains permanently online in the open access (OA) mode.

QA: This Article is published in line with "COPE (Committee on Publication Ethics) and PIE (Publication Integrity \& Ethics)". 


\section{INTRODUCTION}

Cervical cancer (CC) is a malignant tumor of the cervix (the lowermost part of the uterus). According to Oche et al. (2013), it is the second commonest cancer in women globally; with incidence and prevalence varying in different parts of the world (Ntekim, 2012). Even in Nigeria, the relative proportion of malignancies in women varies in different regions of the country, with breast cancer being the commonest malignancy in the South-Western part of the country and CC being the commonest in the Northern part (Abimbola, 2008; Rafindadi et al, 1999). This striking difference is related to the variations in socio-cultural and socio-economic factors between these parts of the country (Ntekim, 2012). Regardless of these differences, there is general agreement that CC is the leading cause of cancer mortality among women in developing countries (FMOH, 2017). For a malignancy that is very preventable, and has such a high potential for cure at low costs with currently available resources when discovered early (Ntekim, 2012), the high frequency and mortality associated with CC in the developing world, Nigeria inclusive, is rather worrisome. However, because the capacity for prevention, early detection, diagnosis and treatment of precancerous and cancerous lesions of the cervix in Nigeria is weak (FMOH, 2017), the figures relating to CC in Nigeria remain very embarrassing. Since 2020 , there has there been a renewed attempt to have a coordinated, ultimately nationwide approach towards screening and early detection of CC in Nigeria (FMOH, 2017; FMOH, 2020). Hopefully, with proper implementation of these recent cervical cancer eradication programmes (FMOH, 2020), the demographics and statistics of CC seen in Nigeria would begin to have a more optimistic outlook. Before that time when CC becomes an eradicated disease (which is the ultimate goal of these screening and prevention programmes), there would remain the need to constantly review its demographic and clinico-pathologic features in Nigeria. This would make the expected changes and societal impacts of increased screening and prevention programmes, easier to track. This study seeks to investigate and identify the clinico-pathologic features of cervical cancer in patients seen and treated at a Comprehensive Cancer Centre in North-western Nigeria.

\section{LITERATURE REVIEW}

Regarding the review of literature, there is available empirical evidence obtained from various studies on clinicalpathological profiling of cervical cancer from different authors across the globe. Extrapolating from the extant literature, cervical cancer has different Histopathological variants as well as different noticeable features at different stages of the disease. It has been unequivocally observed by Raju, Raghuveer and Sheela, (2019) that clinicopathological features vary and are heterogeneous in different studies. Apparently, this has been proven in many clinical researches. For example, Omenai, Ajayi, and Okolo (2021) states that a majority of cervical carcinomas are squamous cell carcinomas and are majorly the large cell nonkeratinizing variant. This was derived from their statistical analysis of 293 cases, which shows that $252(86.0 \%)$ cases were squamous cell carcinoma, 18 cases (6.1\%) were adenocarcinomas, 16 cases $(5.5 \%)$ were adenosquamous carcinomas, and 6 cases $(2.2 \%)$ were adenoid cystic carcinomas, while 1(0.3\%) was a neuroendocrine carcinoma. Similarly, Patil, Deshmukh, Rathid, Kotgire, \& Chavan, (2018) in their study of 150 patients, found that 88 had moderately differentiated squamous cell carcinoma, 24 poorly differentiated, and 32 well differentiated, with adenocarcinoma numbering only six; 98 of these cases were in the age group of 40-59 years, 39 in the age group of 60-80 years, and 13 in 20-39 years group. All the six cases of 
adenocarcinoma were seen in 40-59 years. Relating to clinical features, 96 presented with whitish discharge and 68 with bleeding per vagina. In Ghana, Der et al (2014) found that the commonest (76.9\%) presentation was bleeding per vaginum followed by fungating cervical masses $(12.4 \%)$. Majority $(88.9 \%)$ of the bleeding were unprovoked and in postmenopausal women (98.8\%). The major types of cervical cancers were Squamous cell carcinoma (SCC) (90.1\%) and adenocarcinoma $(5.8 \%)$.

Cervical malignancies were common in the age group of 40-60 years and presented most commonly with bleeding per vagina, as shown by Gaikwad, Valand, \& Agarwal (2016). Also, according to Rana, Singh, Mahajan, and Rana (2019), the most common age group in carcinoma cervix was fifth and sixth decade with history of bleeding per vagina being the most common clinical presentation. Squamous cell carcinoma (SCC) was the most common variant, and $\geq$ Stage III cases constituted the majority, denoting a poor prognosis. Rana et al (2019) further states that late-stage cervical cancer can present with weight loss, appetite loss, fatigue, pelvic pain, heavy vaginal bleeding and bone fracture in cases with metastasis. Vaginal discharge was more commonly seen associated with Adenocarcinoma (AD) than SCC and the recurrence rate was higher than SCC, from the study. The most common type of carcinoma was SCC (80.5\%) and a wide spectrum of its subtypes was seen. Many studies done in the past showed SCC with its variants and AD as common histologic types of cervical carcinoma (Rana et al., 2019). SCC was found to be the most common type constituting $58.2 \%$ of all the cervical carcinomas (Rana et al., 2019).

In another related study, Anorlu (2006) states that in the early stage of the disease, the patients may be asymptomatic or present with bleeding which may take the form of postcoital bleeding, irregular vaginal bleeding (intermenstrual, perimenopausal or postmenopausal bleeding). This may be associated with watery, bloodstained and offensive vaginal discharge (Azeez, Laima, Yahaya, Onuwabuchi, Lawan, and Farouk, 2020). Studies in developing countries have shown that most patients present in late stages (IIB-IVB) of the disease (Azeez et al., 2020; Gaikwad et al., 2016). Late-stage disease presentation and diagnosis has been associated with lack of awareness of screening programmes, geographical inaccessibility, lack of an oncologist, negligence of initial symptoms along with financial constraints (Jain, Shukla, \& Gupta, 2017; Afroj, et al., 2017 cited in Raju, Raghuveer, \& Sheela, 2019). Besides, in our daily clinical assessment of patients, we gathered that late presentation of cancer cases for treatment comes in part from patients' denial of diagnosis, fear of disfigurement of the affected part of the body (to which they attach greater value) and an inclination to delusional persuasion from the religious leaders.

\section{METHOD}

\section{RESEARCH DESIGN}

This study was a retrospective descriptive study carried out at Department of Radiotherapy-and-oncology of Usman Danfodiyo University Teaching Hospital (UDUTH), Sokoto over a 6-year period (January, 2010 to December, 2015). All cases reviewed had histological confirmation of the disease, and they were all initially examined under anaesthesia and staged clinically by the gynaecologists based on clinical staging by Federation of Gynaecologists and Obstetricians (FIGO 2010). UDUTH, Sokoto, is one of the two (2) Comprehensive Cancer Centres in North-western Nigeria, and caters majorly for patients from the host state (Sokoto), nearby Kebbi and Zamfara States, as well as neighbouring Niger and Benin Republics. Also, because the Radiotherapy facilities in Nigeria are quite few and most 
are non-functional over long periods of time (Adewuyi, Campbell, Ketiku, Duronsinmi-Etti, Kofi-Duncan, \& Okere 2013), many Cancer patients get referred to UDUTH, Sokoto, from virtually every state in Nigeria.

\section{PARTICIPANTS}

Participants were cervical cancer patients that received radiotherapy treatment in the department of RadiotherapyOncology UDUTH, Sokoto. The sample consisted of 220 selected case notes of cervical cancer patients that were exposed to radiotherapy treatment. The patients' demographic characteristics include sex, age, marital status, and occupation. Participants were both young and old patients whose ages ranged from 28-87years.

\section{METHODOLOGY}

Ethical clearance was obtained from the Research Ethical Committee of the hospital, with authorization to access the case-folders of all patients who presented with cervical cancer for the six-year period covered. Data was collected from secondary sources which comprised mainly of patients' case notes obtained in the archive of the department of Radio-Oncology UDUTH, Sokoto. The treatment information documented on patients was obtained using a semistructured data extraction form.

\section{DATA ANALYSIS}

Data was analyzed using IBM SPSS version 21.0 and represented in tables, charts and graphs, for statistical analysis. Frequency distributions were generated for all categorical variables analyzed. Means and standard deviations were also determined for quantitative variables

\section{RESULTS}

The results of the study from the review and analysis of 220 cervical cancer patients' case folders accessed in the Department of Radiotherapy and Oncology UDUTH, Sokoto state, is presented in frequency and percentages on the tables below. 
Table 1: Summary of the socio-demographic distribution of the 220 cervical cancer patients studied.

\begin{tabular}{lll}
\hline Variables & Frequency & Percent \% \\
\hline Age group & & \\
$20-29$ & 9 & 4.1 \\
$30-39$ & 27 & 12.3 \\
$40-49$ & 69 & 31.4 \\
$50-59$ & 53 & 24.1 \\
160-69 & 47 & 21.4 \\
$70-79$ & 11 & 5.0 \\
$80-89$ & 4 & 1.8 \\
Marital status & & \\
Married & 176 & 80.0 \\
Single & 7 & 3.1 \\
Separated & 11 & 5.0 \\
Widow & 25 & 12.0 \\
Religion & & \\
Islam & 123 & 56.0 \\
Christianity & 97 & 44.0 \\
Traditional & 0 & 0.0 \\
Educational status & & 52.7 \\
Non-formal education & 116 & 20.9 \\
Primary education & 46 & 17.7 \\
Secondary education & 39 & 5.5 \\
Tertiary education & 12 & 3.2 \\
Not indicated & 7 & 61.4 \\
Occupation & & 15.9 \\
Housewives & 135 & 14.1 \\
Civil servant & 35 & 6.4 \\
Trading & 31 & 2.3 \\
Farmer & 14 & \\
Others & 5 & \\
\hline
\end{tabular}

Table 2: Descriptive summary of the stages of cervical cancer observed in the 220 patients studied

\begin{tabular}{lll}
\hline Stages of CC & N & Percentages \% \\
\hline Stage 1b & & 5.0 \\
Stage 2a & 11 & 15.0 \\
Stage 2b & 33 & 23.2 \\
Stage 3a & 51 & 22.0 \\
Stage 3b & 49 & 20.9 \\
Stage 4a & 46 & 8.6 \\
Stage 4b & 19 & 5.0 \\
Total & 11 & $\mathbf{1 0 0}$ \\
\hline
\end{tabular}

Table 2 represents the various stages of cervical cancer patients were diagnosed with. 
Table 3: Descriptive summary of clinicopathological features of cervical cancer identified in the 220 patients

\begin{tabular}{llc}
\hline Variables & N & Percent \% \\
\hline Clinical features & 110 & \\
Vaginal Bleeding & 103 & 50.0 \\
Foul-Smelling Vaginal Discharge & 67 & 46.8 \\
Fatigue & 65 & 30.5 \\
Lower Abdominal Pain & 30 & 29.5 \\
Weight Loss & 182 & 13.6 \\
Histopathological features & 22 & 82.7 \\
Squamous Cell Cancer & 9 & 10.0 \\
Adenocarcinoma & 7 & 4.1 \\
Clear Cell Carcinoma & & 3.2 \\
Others & & \\
\hline
\end{tabular}

Table 3 represents the various clinical and histological features which were identified from the 220 cervical cancer patients seen in a comprehensive cancer center in the North-western Nigeria. Majority 110 (50\%) of the patients had vaginal bleeding as a presenting symptom, followed by $103(46.8 \%)$ who had foul-smelling vaginal discharge and 67 $(30.5 \%)$ had fatigue. Some patients had multiple symptoms. The most common histological variant was squamous cell carcinoma, accounting for $182(82.7 \%)$, followed by adenocarcinoma $22(10 \%)$ and clear cell carcinoma $9(4.1 \%)$. Stage $1 \mathrm{~b}$ accounted for 11 (5\%), 2a 33 (15.0\%), 2b 51(23.2\%), 3a 49(22.3\%), 3b 46(20.9\%), 4a $19(8.6 \%)$, and 4b for $11(5 \%)$.

\section{DISCUSSION}

Cervical cancer is a public health problem in Nigeria. Like any other disease, it has its own clinical and pathological features which define it and makes it distinct from other diseases. Based on this reality, the purpose of study was to determine the clinical and pathological features of cervical cancer patients seen in a comprehensive cancer center in North-western Nigeria. Reporting therefore on the findings obtained from the review of case notes and folders of patients treated for cervical cancer in a comprehensive cancer center North-western Nigeria, these findings were made regarding the clinicopathological features of cervical cancer.

First and foremost, in the review and analysis of the cases, $80 \%$ of the patients with cervical cancer presented with advanced disease (Stage $2 \mathrm{~b}$ and above), and this reflects what has been discovered in many other similar studies by Anorlu et al (2004), Musa et al, (2016) and Patil et al, (2019). Regarding Histopathological features, the finding was that the most common histological type of cervical cancer was squamous cell carcinoma, accounting for $82.7 \%$, followed by adenocarcinoma $10 \%$. Clear cell carcinoma only accounted for $4.1 \%$ of cases, while others (not specified in the folders) accounted for $3.2 \%$. Squamous cell carcinomas arise from squamo-columnar junction and may be either keratinizing or non-keratinizing type (well-differentiated or poorly differentiated carcinoma). The findings of this study support similar results from previous studies which disclosed that majority of cervical cancer cases are identified to be squamous cell carcinomas and these are majorly large cell nonkeratinizing variants. This was stated in the statistical analysis of 293 cases, which shows that 252(86.0\%) cases studied represents squamous cell carcinoma, 18 cases $(6.1 \%)$ were adenocarcinomas, 16 cases $(5.5 \%)$ were adenosquamous carcinomas, and 6 cases $(2.2 \%)$ were 
adenoid cystic carcinomas, and 1(0.3\%) was a neuroendocrine carcinoma (Omenai, Ajayi, and Okolo, 2021). Likewise, Patil, Deshmukh, Rathid, Kotgire, and Chavan, (2018) in a study of 150 patients, found that 88 cases had moderately differentiated squamous cell carcinoma, 24 poorly differentiated, and 32 well differentiated. Furthermore, others have found that $80-90 \%$ of cervical carcinoma was squamous cell carcinoma type and the rest were adenocarcinoma (Ntekim, 2012; Adewuyi, 2001). From this study and others, it is obvious that squamous cell carcinoma is the most common histological feature of cervical cancer seen in patients. Many other studies have also clearly shown that patients with this type of cervical cancer have the propensity for a better prognosis, when compared to those with the adenocarcinoma type (Hu, Wang, Liu, Meng, \& Zhang, 2018, Jung, et al., 2017; Lee et al., 2010).

Regarding the clinical features of the 220-case reviewed, the results indicate that $110(50.0 \%)$ had vaginal bleeding, making it the most common feature of cervical cancer patients. This finding corresponded with other available literature evidence explained by researchers from different countries, who agree that cervical malignancies were common in the age group of 40-60 years and presented most commonly with bleeding per vagina (Gaikwad, Valand, \& Agarwal, 2016; Rana, Singh, Mahajan, and Rana, 2019; Ntekim, 2012; Oguntayo et al., 2011; Adewuyi, 2007). Other clinical features seen were foul-smelling vaginal discharge 103(46.8\%0, fatigue 67(30.5\%), lower abdominal pain 65(29.5\%) and weight loss 30(13.6\%). The clinical features of cervical cancer identified in the cases reviewed are features mostly seen in patients with advanced stages of the disease. This assertion is predicated on evidence from previous studies which found vaginal discharge, weight loss, appetite loss, fatigue, and pelvic pain as common features of cervical cancer (Azeez, Laima, Yahaya, Onuwabuchi, Lawan, and Farouk, 2020; Rana et al., 2019), and agree that these clinical features identified were found more commonly in patients presenting late-stage cancers, particularly stages (IIB - IVB). From the above discussion, this study has clearly buttressed the findings of many previous studies which state that in developing countries, most patients present with advanced disease (FIGO IIB-IVB) of cervical cancer (Azeez et al., 2020; Gaikwad et al., 2016; Musa et al., 2016; Adewuyi et al., 2010; Anorlu et al., 2004).

Sadly, there is a general agreement that cervical cancer is the leading cause of cancer mortality among women in developing countries, including Nigeria (FMOH, 2017). Better still, cervical malignancy can be cured at low costs if the affected patient has adequate financial resources when discovered early (Ntekim, 2012). This is because there are in Nigeria numerous oncologists, and there are anticancer drugs and radiotherapy centres for cancer treatment. Notwithstanding, cervical cancer remains one of the major public health problems in Northern Nigeria. This is further compounded by the fact that late disease presentation is a common phenomenon observed among patients seen almost on a daily basis with diagnosis of cancer. The late-stage disease presentation and diagnosis has been associated with lack of awareness of screening programmes, geographical inaccessibility, lack of an oncologist, negligence of initial symptoms along with financial (Jain et al., 2017; Afroj, et al., 2017 cited in Raju et al., 2019). Besides, in our daily clinical interaction with patients diagnosed of cancer, we have gathered that late presentation of cancer cases for treatment also partly comes from patients' denial of diagnosis, beliefs in witchcraft, fear of disfigurement of the affected part of the body (to which they attach greater value), fear of stigmatization, and strong beliefs in prayer and faith-healing as an alternative to seeking medical help from trained healthcare providers. 


\section{CONCLUSION}

Cervical cancer remains a malignancy of major public health concern in Nigeria. Although the commonest histological type seen is the squamous cell carcinoma, which is known ideally to have a much better prognosis compared to the less common adenocarcinoma, the benefits of this differential in prognosis is somewhat eroded in our clinical settings as the majority of patients with cervical cancer still present with clinical features like vaginal bleeding, vaginal discharge, fatigue, lower abdominal pain and fatigue, which are clearly indicative of late stages of the disease; thus compounding management and worsening their prognosis. This is a reflection of the poor utilization of screening services for early detection. Extrapolating from the study findings, it is therefore important to stress the need to intensify campaign for education and enlightenment, to create more awareness on cervical cancer screening. This will enhance early detection and treatment, helping to achieve better treatment outcomes.

\section{CONFLICT-OF-INTEREST}

The authors have no Conflict of Interest to declare.

\section{FUNDING}

The Research was fully self-sponsored. 


\section{REFERENCES}

Abimbola, O.K.. (2008). Cervical cancer and its control in Nigeria: challenges and the way forward. A thesis submitted in partial fulfilment of the requirement for the degree of Master of Public Health, Royal Tropical Institute, Amsterdam.

Adewuyi SA, Campbell OB, Ketiku Kk, Duronsinmi-Etti FA, Kofi-Duncan JT and Okere PC. Current status of Radiation oncology facilities in Nigeria. West African Journal of Radiology 2013; 20:30-6

Adewuyi, S.A., Shittu, O.S., Rafindadi, A.H., Zayyan, M.S., Samaila, M.O.A. and Oguntayo, A.O. (2010). Cisplatin chemotherapy for Homeostasis in bleeding cervical cancer: experience from a resource-poor setting. Nigerian Postgraduate Medical Journal; 17(2):122-7.

Adewuyi, S.A., Shittu, S.O., Rafindadi, and A.H. (2008). Sociodemographic and clinicopathologic characterization of cervical cancers in northern Nigeria. European Journal Gynaecologic Oncology; 29(1):61-4. PMID: 18386466.

Adewuyi, S.A. (2007). Cervical cancer in HIV seropositive patients. Annals of African Medicine; 6:41-2

Afroj, S., Banu, M.A., Sultana, S., Jahan, R., Rahman, S. and Begum, N. (2017). Clinicopathological profile of cervical cancer patients attending in a specialized hospital. Journal of Dhaka Medical College; 26(2): 117121. DOI: http://dx.doi.org/10.3329/jdmc.v26i2.38826

Airede, L.R. and Malami, S.A. (2005). A five-year review of female genital tract malignancies in Sokoto, Northwestern Nigeria. Mary Slessor Journal of Medicine; 5:51-6.

Anorlu, R.I., Orakwue, C.O., Oyeneyin, L. and Abudu, O.O. (2004). Late presentation of patients with cervical cancer to a tertiary Hospital in Lagos: what is responsible? European Journal Gynaecological Oncology; 25(6):729-32. PMID: 15597852.

Azeez. O.A., Laima, C.H., Yahaya, U.R., Onwuachi, E., Lawan, A., and Farouk, H.U. (2020). Clinicopathological analysis of cervical cancer in Gombe, North East Nigeria; a ten-year retrospective study. JMSCR Vol. 08 Issue03, P691-695. Retrieved from DOI: https://dx.doi.org/10.18535/jmscr/v8i3.118.

Babarinsa, A., Akang, E.E, Adewole, I.F. (1998). Pattern of gynecological malignancies at the Ibadan cancer registry (1976-1995). Nigerian Quarterly Journal of Hospital Medicine; 8:103-6.

Brenna, S.M., Zeferino, L.C., Pinto, G.A., Souza, R.A., Andrade, L.A., Vassalo, J., et al. (2002). C-Myc protein expression is not an independent prognostic predictor in cervical squamous cell carcinoma. Brazil Journal of Medical and Biological Resources; 35:425-30.

Chan, P.G., Sung, H.Y. and Sawaya, G.F. (2003). Changes in cervical cancer incidence after three decades of screening US women less than 30 years old. Obstetrics and Gynecolog; 102:765-73.

Der, E.M., Adu-Bonsaffoh, K., Tettey, Y., Kwame-Aryee, R.A., Seffah J.D., Alidu, H., and Gyasi, R.K. (2014). Clinico-pathological characteristics of cervical cancer in Ghanaian women. Journal of Medical and Biomedical Sciences; 3(3): 27-32. Retrieved from doi: http://dx.doi.org/10.4314/jmbs.v3i3.5

Federal Ministry of Health (FMOH, 2017-2021). National strategic plan for prevention and control of cancer of the cervix in Nigeria.

Federal Ministry of Health (FMOH). National training manual for cervical cancer secondary prevention and control. Unitaid and CHAI, 2020. 
Gaikwad, S.L., Valand, A.G., Agarwal, and N.U. (2016). Clinico-histopathological analysis of lesions of uterine cervix in Ambejogai city of Maharashtra: A 2-year study at tertiary level hospital. Journal of Diagnostic Pathology and Oncology; 1(2):32-35. Retrieved from https://www.ipinnovative.com

Giorgi, R.P., Sideri, M., Carozzi, F.M., Vocaturo. A., Buonaguro F.M., Tornesello, M.L., et al (2012). HPV type distribution in invasive cervical cancers in Italy: Pooled analysis of three large studies. Infectious Agents and Cancer; 7:26.

Hu, K.., Wang, W., Liu, X. et al. (2018). Comparison of treatment outcomes between squamous cell carcinoma and adenocarcinoma of cervix after definitive radiotherapy or concurrent chemoradiotherapy. Radiation

Oncology; $\quad$ 13, 249 retrieved from https://doi.org/10.1186/s13014-018-1197-5

Jung, E.J., Byun, J, M, Kim, Y.N., et al (2017). Cervical adenocarcinoma has a poorer prognosis and a higher propensity for distant recurrence than squamous cell carcinoma. International Journal of Gynecologic Cance ; 27:1228-1236.

Lee, Y., Choi, C.H., Lee, J., Kim, B., Lee, J., Bae, D. (2011). A comparison of pure adenocarcinoma and squamous cell carcinoma of the cervix after radical hysterectomy in stage IB-IIA. Gynecololgic Oncology; Vol 120 Issue 3, p439-443. Retrieved from DOI: https://doi.org/10.1016/j.ygyno.2010.11.022

Mohammed, A., Ahmed, S.A., Oluwole, O.P. and Avidime, S. (2006). Malignant tumours of the female genital tract in Zaria, Nigeria Annals of African Medicine; 5:93-6.

Musa, J., Nankat, J., Achenbach, C., Shambe, I. et al (2016). Cervical cancer survival in a resource-limited settingNorth Central Nigeria. Infectious Agents and Cancer, 11. 10.1186/s13027-016-0062-0.

Ntekim, A. (2012). Cervical Cancer in Sub Sahara Africa, Topics on Cervical Cancer with an Advocacy for prevention. In R. Rajamanickam (Ed.), InTech, Available on: http://www.intechopen.com/books/topics-oncervical-cancer-with-an-advocacy-for-prevention/cervical-cancerin-sub-sahara-africa

Oche MO, Kaoje AU, Gana G, Ango JT. Cancer of the cervix and cervical cancer screening: current knowledge, attitude and practices of female health workers in Sokoto, Nigeria. International Journal of Medicine and Medical Sciences. 2013; 5(4):184-190. DOI: 10.5897/IJMMS2013.0886i

Oguntayo, O., Zayyan, M., Kolawole, A, Adewuyi, S., Ismail, H., Koledade, K. (2011). Cancer of the cervix in Zaria, Northern Nigeria. Ecance Medical Science; 5. Retrieved from https://www.ncbi.nlm.nih.gov/pmc/articles/PMC3223952/

Patil N, Deshmukh V, Rathid A, Jyoti D, Chavan S. Clinicopathological Correlation of Cervical Carcinoma: A Tertiary Hospital-based Study. International Journal of Scientific Study 2019; 6(10):1-4.

Rafindadi AH, Ifenne DI, Shittu SO, Bako AU and Olasinde TA 1999. A study of some aetiological factors in 41 cases of cancer of the cervix uteri in Zaria. Nigerian Quarterly Journal of Hospital Medicine, 9 p 87-89.

Raju. K., Raghuveer, C.V., and Sheela, S.R. (2019). Clinicopathological correlation of invasive squamous cell carcinoma of uterine cervix: A cross-sectional study. Biomed. Res. Ther; 6(11):3443-3451.

Wang, M., Zhou, Z., and Han, W. (n.d.). Clinicopathological Characteristics and Prognostic Factors for Cervical Adenocarcinoma: A Population Based Study. DOI: https://doi.org/10.21203/rs.3.rs-122266/v1 